\title{
Curriculum Approval Time Lag in Public Comprehensive Universities
}

\author{
Janet L. Applin \\ Western Kentucky University
}

\begin{abstract}
Curriculum in higher education is critical to the life of a public university and the reputation of institutions is often based on the quality and innovation of the curriculum. This article describes curriculum approval practices from 19 comprehensive institutions across the Southeastern U.S. Curriculum approval practices were evaluated to determine similarities, differences and the time lag of internal curriculum approval. Document analysis was conducted on publicly available documents related to curriculum approval from each university and analyzed using a constant comparative method. Results and implications are discussed.
\end{abstract}

Keywords: Curriculum, Comprehensive Universities, Time Lag

\section{INTRODUCTION}

The heart of a university should be its curriculum and the fields of study that are provided to students. Curriculum does not just appear but must be developed based on the existing literature and research in the respective fields, the needs of its constituents and the thoughtful expertise of those delivering the curriculum. Faculty must continually revise their curriculum to keep up with advances in their respective fields and the demand that exists for their content and credentials. However, developing new and revised curriculum requires faculty to seek the approval of multiple entities prior to implementing the change. These multiple approval levels have developed over time and often hinder faculty in making sure their curriculum is state-of-the-art. The literature on the curriculum approval process in higher education is scant. Available literature examines effective curriculum development frameworks and strategies for curriculum development but not the approval process itself (Lattuca \& Stark, 2009; Mestenhauser \& Ellingboe,1998). Literature searches examining practices for curriculum approval processes in higher education result in only a very few opinion and editorial pieces (Kilbourne, 2012; Small, 2015). The process is an agonizingly slow one, typically taking a full academic year for full approval and implementation, for programs seeking to innovate and attract $21^{\text {st }}$ century students and, as Kilbourne (2012) noted "it is unfortunate that many colleges, which are charged with preparing the next generation of entrepreneurs and innovators, embrace a culture of time-consuming, unhurried progress when it comes to curriculum, personnel, and governance. Nowhere is this more evident than in their committee structures." No empirical literature was found to support the current committee structures common in academia. One may argue that the current unhurried shared governance process is necessary to maintain a system of quality with checks and balances so that existing curriculum is not duplicated, and institutional integrity is maintained so as not to be confused with for-profit diploma mills. On the other hand, Selingo 
(2015) notes that the way shared governance is practiced in academia in comprehensive universities in the United States often leads to inefficiency and redundancy and is one of the barriers to innovation at public comprehensive universities. Often debated is the definition of "shared governance." Olson (2009) clarifies the term: "True shared governance attempts to balance maximum participation in decision making with clear accountability. ... Genuine shared governance gives voice (but not necessarily ultimate authority) to concerns common to all constituencies as well as to issues unique to specific groups."

Over fifty years ago, the American Association of University Professors (AAUP), the American Council on Education (ACE), and the Association of Governing Boards of Universities and Colleges (AGB) adopted a statement directed to governing board members, administrators, faculty, students and other persons noting that, "colleges and universities of the United States had reached a stage calling for appropriately shared responsibility and cooperative action among components of the academic institution." The components of the statement on shared governance was jointly formulated by the AAUP, ACE, and the AGB and adopted by each of the organizations in 1966 and 1967. In 1990 the AAUP updated that statement to remove gender-specific references that had been in the original statement (AAUP, n.d.). For over 50 years, the three respective organizations have recognized the statement as, "a significant step forward in the clarification of the respective roles of governing boards, faculties, and administrators." Within this joint statement, it is noted that faculty have the primary responsibility for curriculum, subject matter and methods of instruction, among other responsibilities (AAUP, n.d.). The issues raised in shared governance related to curriculum approval are not exclusive to universities in the United States. Desha, Hargroves, and Smith (2009) found similar problems in the lengthy curriculum approval structure in Australian universities related to engineering education for sustainable development.

For the purpose of this study, shared governance refers to the committee structures and university personnel in those structures required for curriculum approvals for revision and the creation of new curriculum. Given Olson's (2009) clarification of the term, it is hardly surprising that the time it takes to develop, seek approval, and implement curriculum changes is lengthy. As previously noted, it is common for curricular changes to take a full year from development to implementation and that is only if there are no objections at any level of approval.

Often, faculty and even senior level academics may have no knowledge of how new programs or new courses are approved. Not surprisingly, once they are introduced to the flow and the time lag of curriculum approval, they choose to leave their program as is, sometimes obsolete and out of date, rather than going through the arduous process. This author's personal experience with serving as an advisory member in an administrative position to multiple curriculum committees, and subsequently as chair to a university-wide curriculum body, led to questions about whether the approval process is as arduous at other institutions and whether there is an existing research base for the process. Why does the process take so long and require so many different approval levels? Are all of the levels necessary? Is the current committee structure based on any research regarding best practices to approve new curricula?

Desha, Hargroves, and Smith (2009), while examining curriculum renewal in engineering education in Australian universities refer to this as, "time lag dilemma." A time lag dilemma, according to the authors, exists when the "usual or standard timeframe to update curriculum may be too long to meet changing industry, regulatory, and accreditation requirements" (Desha, Hargroves, Smith, 2009). They discuss factors putting pressure on engineering departments to more rapidly update their curriculum including, "legislation and regulations; increased accreditation requirements; shifts in industry demands for graduates; and shifts in the demands of the students themselves." The authors go on to state that using the standard or usual methods and timelines to pursue curriculum change may expose their departments to risks in regard to student demand for the programs as well as the viability of their programs and they present a case for rapid curriculum renewal (RCR) to respond to the demands of their industry (Desha, Hargroves, \& Smith, 2009). This author's experience leads one to contend that this "time lag dilemma" is present not only in engineering education, but in most disciplines across higher education and particularly at public comprehensive universities given our shared governance traditions and committee structures that lead to curriculum approval and implementation. 
In our rapidly changing world, the pace of curriculum development and approval in higher education does not keep up with the exigencies of the marketplace or our competitors, nor does it serve our regional communities as is demanded by our constituents in workforce and economic development (Dorrer, 2015). Some may argue that speeding up the time frame for curriculum renewal will lead to programs that are poorly developed, duplicate existing curriculum, and possibly harm our students and constituents in the long run. Here it is argued that there is a need for curriculum to be ever evolving and improving to meet the demands of new technology, new business models, and new mandates from a discipline's and a university's governing and accrediting bodies, and perhaps most important, emergent research in our various fields. One wonders how academic programs are to remain relevant when the fields are changing more rapidly than the curriculum, we use to educate the future practitioners in those fields.

\section{STATEMENT OF PURPOSE}

As alluded to in the literature review, there may exist a time lag in the curriculum approval process in higher education. However, due to the scarcity of empirical literature regarding best practices in curriculum approval, this study seeks to explore and determine what constitutes "normal" at comparable size public comprehensive universities in terms of curriculum approval committee structures and time lag for internal curricular changes and what implications of the norm may exist.

\section{RESEARCH DESIGN}

Within a Basic Qualitative Multi-Case Study design, document analysis was conducted on publicly available documents related to curriculum approval from each target university and analyzed using a constant comparative method. According to Stake (2005), case study is more of a choice as to what is being studied than it is a methodological choice. In this study, the "what" is the bounded system of curriculum approval at public comprehensive universities as studied through document analyses. Bowen (2009) defines document analysis as, "a systematic procedure for reviewing or evaluating documents both printed and electronic (computer-based and internet-transmitted) material." Bowen (2009) goes on to note that document analysis requires, like other analytical methods in qualitative research, "that data be examined in order to elicit meaning, gain understanding, and develop empirical knowledge," but cautions about the disadvantages of document analysis such as insufficient detail; low retrievability; and biased selectivity. The goal here was to construct meaning from the analysis of specific cases within the boundaries of committees that approve curriculum as is common in a qualitative multi-case study. Yin (2014) discusses how case studies investigate phenomenon within the real-life context. The phenomenon studied here is the curriculum approval process. The real-life context is the curriculum approval steps used in that process.

With Bowen's (2009) cautions in mind, documents were retrieved through the websites of each target institution. While document analysis is most often used in combination with other qualitative research methods as a means of triangulation, in the present study document analysis alone was utilized due to its efficiency, availability, cost-effectiveness, lack of obtrusiveness and reactivity, stability, exactness, and coverage - all outlined as advantages of document analysis by Bowen (2009). All documents analyzed for this study were publicly available on the institutions' websites. The author's home institution's Internal Review Board reviewed an application for the research and approved it as an exempt study due to the public availability of the documents analyzed.

\section{Sample}

The present study evaluated the curriculum approval processes at 19 public comprehensive universities across the mid-west and south-east regions of the U.S. to evaluate institutional procedures for governing internal curriculum approval. The study investigated the steps involved in the process, the types of committees required, the timelines required, and the stakeholders involved. Results raised questions related to curriculum development and approval, in particular, the time lag of the process. 
The 19 universities were chosen because they are considered "benchmark," or "peer," institutions. "Peer," institutions are chosen by individual institutions and submitted to the Integrated Postsecondary Education Data System (IPEDS) in the National Center for Education Statistics (NCES) (2018) each year as a comparison group. These are typically those institutions similar in finances, enrolments, graduation rates, geographic location, etc.

\section{Data Collection}

The main websites of the target institutions were accessed, and curriculum related search terms were entered into the main page website search box. Search terms entered were: CURRICULUM; CURRICULUM APPROVAL; and CURRICULUM FLOW. Documents collected that outlined the curriculum approval process of the institutions included institutional curriculum flow charts; course curriculum/modification request forms; faculty handbook pages with instructions for curriculum approval; academic approval matrices; new course proposal forms; timeline documents for curriculum approval; cover memos for curriculum changes; new course proposal instructions; and curriculum action forms. Documents were deemed acceptable for this study if they contained information that outlined steps to curriculum approval for internal curriculum change. External curriculum approval steps such as those required by state agencies, regional higher education accreditation bodies, and specific professional bodies, for new or significantly changed curriculum were not examined for the current study. External approvals are typically required for new program curriculum and/or substantively changed curriculum and require many more steps and outside body approvals such as from state departments of education, regional accrediting bodies, and state councils on postsecondary education. This study was interested only in the time it takes to garner approvals within the institutions' internal approval processes.

\section{Data Management}

Documents accessed were stored in electronic file folders, and a spreadsheet was created to record specific curriculum approval steps from each institution for preliminary coding. Approval steps were then categorized and analyzed for similarities and differences and emergent themes and timelines were constructed. Institutions were coded so as to protect the identity of each university.

\section{Limitations}

Document analysis alone has some inherent disadvantages such as insufficient detail; low retrievability; and biased selectivity (Bowen, 2009). This author acknowledged these inherent disadvantages and kept them at the forefront during analysis. However, it is not out of the realm of possibility that the disadvantages had an effect on the validity of the results. These disadvantages were, however, negated because the author is intimately familiar with the curriculum approval process at a similar public comprehensive university. Insufficient detail may have been an issue because there was no standard form that was common to each institution. Insufficient detail was negated as much as possible through the constant comparison and coding of categories and development of themes. Low retrievability was not an issue in this study as documents were readily located and publicly available from each institution that outlined the curriculum approval steps. Biased selectivity, given this author's familiarity with the process, could have come in to play during document location but it is believed that this could have actually been a benefit rather than a limitation.

\section{Data Analysis}

Document analysis was inductive, ongoing, and continuous using open coding, axial coding, and constant comparison (Corbin \& Strauss, 2015). Open coding was the initial stage where the actual steps indicated by the document analysis were listed. Next, axial coding was utilized to determine categories and subcategories or themes. Of the nineteen institutions examined, the average number of committee steps to curriculum approval was 7.9 with a range of 6 to 11 steps. Five of the nineteen have 6 steps to curriculum approval; three have 7 steps; four have 8 steps; two have 9, 10, and 11 steps respectively. Nine of the institutions implement an electronic curriculum approval process using commercially available 
software such as Curriculog (2018) and Course Leaf Online Curriculum Management System (2018) or an electronic system that is designed by their own information technology personnel. Two of those nine use an electronic system for graduate-level curriculum approval only but not undergraduate curriculum approval. One of the institutions, at the time of data collection, was transitioning to an electronic system for their graduate college. Companies that develop and market the electronic systems claim to reduce the time it takes to move curriculum through the process, or to, "revolutionize" the process, however it is the timelines of the committees' calendars, rather than the hard copy paperwork that results in a time lag in this author's personal experience. While they do reduce hard copies of documents moving through the system and allow multiple personnel to review documents in real time, they do not affect the calendars of the committees that are required for approval. It is standard for most standing committees in academia to meet on a monthly basis during the academic year. For a curriculum developer or proponent to move a proposal through several committee approvals, one must have impeccable timing and luck to meet the deadlines and navigate the calendars of the multiple committees. It is rare for one proposal to make it through two committees in a month's time in this author's experience. Thus, a time lag of at least 6 academic months is created before a program change can be fully approved. Once a curricular change is approved at every level or step, the work of changing advising documents, marketing and advertising strategies, and internal computerized systems to reflect the approved changes begins. This is a best-case scenario only if there are no objections to the proposed curriculum to further add to the time lag.

\section{THEMES}

The ongoing and continuous induction analysis resulted in emergent themes that were present in the institutions analyzed. Categories, or approval steps, from each institution, were coded and themes emerged: Universal Approval Steps - steps that 100\% of the institutions use; Common Approval Steps steps that $75-90 \%$ of the institutions use; Typical Approval Steps - steps that $50-75 \%$ of the institutions use; Non-Typical Approval Steps - steps that $25-50 \%$ of the institutions use; and Rare Approval Steps - steps that less than $25 \%$ of the institutions use. Note that there were no approval steps that would fall into a category of between 90 and 100 percent. Many of the approval committees served the same purpose yet go by different names and these shared purposes were included in the analyses.

\section{Universal Approval Steps}

There are three approval steps that are referred to here as Universal Approval Steps and all of the institutions universally require for curriculum approval: Academic Programs; Academic Departments; and the Academic College. Regional accreditors of institutions of higher education put great value on curriculum being developed and approved by faculty members with expertise in their given fields (SACSCOC) so it is not surprising that faculty in Academic Programs develop and revise curriculum and the program faculty approve the curriculum as a first step in the process universally. The next Universal Approval Step is Academic Departments. Once program faculty approve curricular changes, the program's department must also approve the changes before it moves forward in the process. The third Universal Approval Step is the College-wide approval. While all of the institutions require these three approval steps, all of the institutions evaluated have additional approval steps beyond these three first steps.

\section{Typical Approval Steps}

The next level of approvals appearing most frequently is referred to as Typical Approval Steps which 50 to $75 \%$ of the institutions require. Over half of the institutions require curriculum approval through an Undergraduate Curriculum Committee or Graduate Curriculum Committee and over half of the institutions require approval through Academic Affairs. Again, all universities require additional steps beyond the Typical Approval Steps. 


\section{Non-Typical Approval Steps}

Beyond the Typical Approval Steps are those that fall in the theme of Non-Typical Approval Steps. These are those steps that are required of 25 to $50 \%$ of the institutions examined and include approval through the Senate or Faculty Governance Body; the President or Chancellor; the Board of Regents or Board of Trustees; Deans; and Educator Preparation Committees if applicable.

\section{Rare Approval Steps}

Less than 25\% of the institutions require steps that fall into the theme of Rare Approval Steps. These include approval by bodies such as the Library; the Registrar; an Academic Standards Committee; a Writing Committee; an Academic Council; the UUPC Chair; an Independent Course Committee; a Program Committee; a Faculty Council; a Faculty Executive Committee; and/or an Honors Curriculum Committee.

Figure 1 provides a heat map of each institution and their curriculum approval steps. A heat map is a visualization tool for large amounts of data and uses color (here in grayscale) the way a bar graph uses height and width. The heat map is particularly useful for this study's data in that it can show all of the institutions and all of the steps required for curriculum approval as opposed to only averages in a smaller space. Not only can you see which steps are most frequently occurring, but you can also get a sense of which of the institutions may be outliers because of the "rare" steps that they use. The heat map was constructed using "R," an open source "language and environment for statistical computing and graphics" (The R Project for Statistical Computing, n.d.). 


\section{FIGURE 1 \\ HEATMAP OF STEPS IN THE APPROVAL PROCESS}

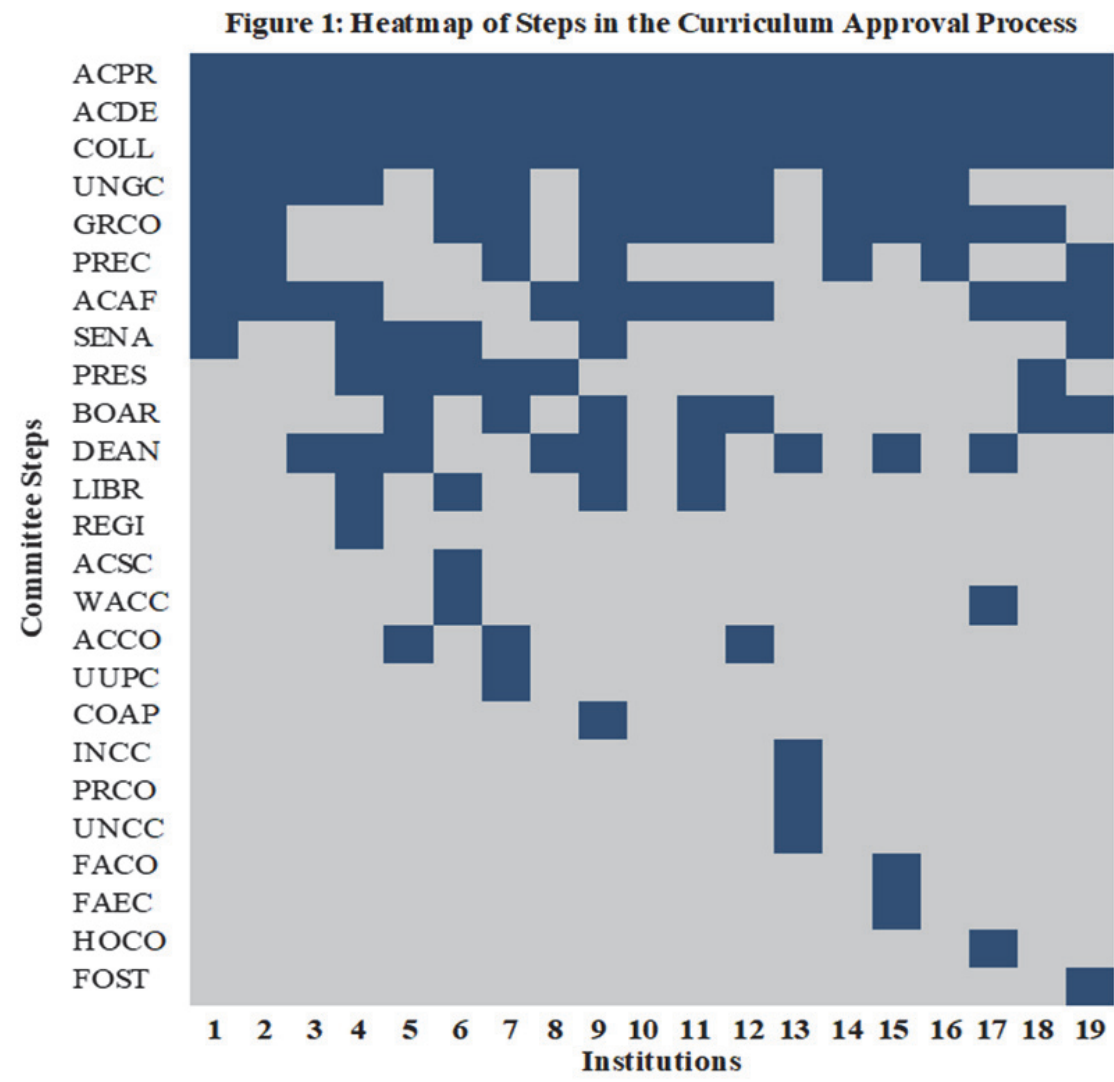

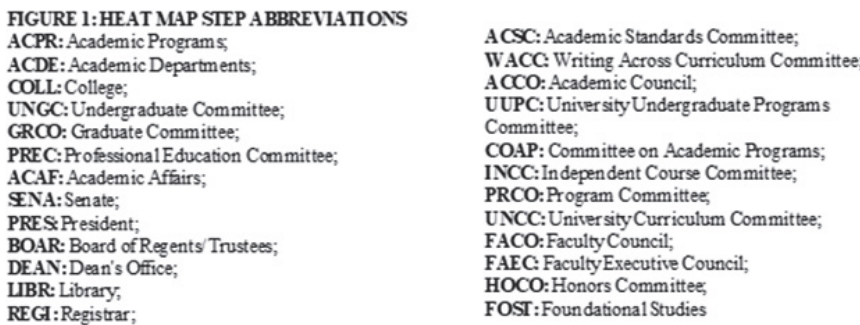

\section{DISCUSSION}

The purpose of this study was to determine what is, "normal," at comparable size public comprehensive universities in terms of curriculum approval committee structures and time lag for internal curricular changes. Through document analysis from 19 institutions, it was found that approvals required for internal curriculum changes range from six committee steps to eleven committee steps at comparable public comprehensive institutions. Themes emerged based on the type of committees required to garner approval: Universal Steps; Typical Steps; Non-Typical Steps; and Rare Steps. Given that university-wide committees typically meet on a monthly basis throughout the academic year in a shared governance structure, this study indicates that internal curriculum approval can take up to eleven months if there are no objections at any level. Constructing meaning from this data leads one to conclude that the time lag of our current curriculum approval process at public comprehensive institutions is affecting our ability to compete within our academic industry. The time lag between program faculty innovation of their curriculum and actually implementing something new, innovative, and responsive to the needs of 
prospective students is unacceptable. Institutions of higher education, particularly public comprehensive universities as were studied here, are under increasing pressure to perform by their own states as well as the federal government using key metrics such as graduation rates and retention rates (Yin, 2015). How are we to attract, retain, and graduate students if we are not providing them with the types of skills and knowledge that are demanded in their chosen industries? Continuing to maintain the status-quo of our curriculum and expecting it to attract students who will enter the workforce in the coming decades is detrimental to the survival of public comprehensive institutions. The curriculum approval process and time lag must be a part of this conversation if we are to thrive into the coming years. Selingo (2015) is correct when he states that "skepticism of anything new and opposition to change run deep through higher education...". The results of this study provide us with a starting point to create a commitment to innovate and to do it in a way that maintains our institutional integrity while keeping up with the pace of our competitors, our state and local government requirements and most importantly, the needs of constituents - our current and future students.

\section{Directions for Future Research and Implications for Policy and Practice}

This study has important implications for future research and policy and practice development. Using the themes developed here, we now have a starting point to begin discussions of the curriculum approval process and future researchers can further describe the process using shared language. By having clear descriptions, practices in curriculum approval can be measured and researchers can discern how practices affect those all-important metrics of retention and graduation rates. Future research may try to find a way to assess whether time lag is truly problematic as suggested by this study. Practices at different types of universities - flagship public universities, private universities, for-profit universities - may be described and compared to the practices at public comprehensive universities. Perhaps most important, policy makers and faculty can begin to construct best practices in curriculum approval for serving the students and constituents of our universities.

\section{REFERENCES}

American Association of University Professors. (n.d.). Statement on government of colleges and universities. Retrieved from https://www.aaup.org/report/statement-government-colleges-anduniversities.

Bowen, G.A. (2009). Document analysis as a qualitative research method. Qualitative Research Journal, 9(2), 27-40.

Corbin, J., \& Strauss, A. (2015). Basics of qualitative research: Techniques and procedures for developing grounded theory, $4^{\text {th }}$ Ed. Thousand Oaks, CA: SAGE.

Curriculog Curriculum Management. (2018). DIGARC. Retrieved from https://www.digarc.com/solutions/curriculum-management/

Desha, C.J., Hargroves, K.C., \& Smith, M.H. (2009). Addressing the time lag dilemma in curriculum renewal towards engineering education for sustainable development. International Journal of Sustainability in Higher Education, 10(2), 184-199.

Dorrer, J. (2015). Analyzing labor markets in real time: Positioning comprehensive universities for a dynamic economy. In M. Schneider and K.C. Deane (Eds.), The university next door: What is a comprehensive university, who does it educate, and can it survive New York, NY: Teachers College Press.

Fuller, A. (2012, September 10). In selecting peers for comparison's sake, colleges look upward. The Chronicle of Higher Education. Retrieved from https://www.chronicle.com/article/in-selectingpeers-for $/ 134228$

Heath, H., \& Cowley, S. (2004). Developing a grounded theory approach: a comparison of Glaser and Strauss. International Journal of Nursing Studies, 41(2), 141-150.

Kilbourne, J. (2012, October 8). Moving at the speed of academe. Chronicle of Higher Education. Retrieved from http://chronicle.com/article/Moving-at-the-Speed-of-Academe/134890. 
Lattuca, L.R., \& Stark, J.S. (2009). Shaping the college curriculum: Academic plans in context. San Francisco, CA: Jossey-Bass.

Leepfrog. (2018). Course Leaf Curriculum Website. Retrieved from https://www.leepfrog.com/courseleaf/curriculum/

Mestenhauser, J.A., \& Ellingboe, B.J. (1998). Reforming the higher education curriculum: internationalizing the campus. Phoenix, AZ: Onyx Press

Merriam, S.B., \& Tisdell, E.J. (2016). Qualitative Research, $4^{\text {th }}$ Ed.: A guide to design and implementation. San Francisco, CA: Jossey-Bass.

National Centre for Education Statistics (NCES). (2018). Integrated Postsecondary Education Data System. Retrieved from https://nces.ed.gov/ipeds/use-the-data.

Olson, G.A. (2009, July 23). Exactly what is 'shared governance'? The Chronicle of Higher Education.

Retrieved from https://www.chronicle.com/article/Exactly-What-Is-Shared/47065

R Project for Statistical Computing. (2018, July). Retrieved from https://www.r-project.org/

Selingo, J.J. (2015). Opportunities for innovation: Reimagining the next decade of higher education for public comprehensive universities. In M. Schneider and K.C. Deane (Eds.). The university next door: What is a comprehensive university, who does it educate, and can it survive? New York, NY: Teachers College Press.

Small, A. (2015, October 13). A geek's guide to academic committee work: Mastering the dark art of curricular kung-fu. Chronicle of Higher Education. Retrieved from http://chronicle.com/article/A-Geeks-Guide-to-Academic/233725.

Southern Association of Colleges and Schools Commission on Colleges. (2018). Retrieved from http://www.sacscoc.org/.

Stake, R.E. (2005). Qualitative case studies. In N.K. Denzin \& Y.S. Lincoln (Eds.), The Sage handbook of qualitative research ( ${ }^{\text {rd }}$ ed.). (pp.443-466). Thousand Oaks, CA: Sage.

Yin, M.L. (2015). Rethinking student outcomes: Constructing predicted and adjusted graduation and retention rates for comprehensive universities. In M. Schneider and K.C. Deane (Eds.). The university next door: What is a comprehensive university, who does it educate, and can it survive? New York, NY: Teachers College Press.

Yin, R.K. (2014). Case study research: Design and methods $\left(5^{\text {th }}\right.$ Ed.). Thousand Oaks, CA: Sage. 